\title{
Nephrotic Syndrome-Remission, Partial Remission
}

National Cancer Institute

\section{Source}

National Cancer Institute. Nephrotic Syndrome-Remission, Partial Remission. NCI

Thesaurus. Code C123124.

Nephrotic syndrome in which proteinuria has decreased by at least $50 \%$ and below the nephrotic range cutoff from disease onset, but does not normalize following a defined course of treatment. 